\title{
"I wish they could be in my shoes": patients' insights into tertiary health care for type 2 diabetes mellitus
}

This article was published in the following Dove Press journal:

Patient Preference and Adherence

17 November 2015

Number of times this article has been viewed

\author{
Jacqueline D Cotugno' \\ Maree Ferguson ${ }^{1,2}$ \\ Hazel Harden ${ }^{3}$ \\ Shoni Colquist ${ }^{3}$ \\ Annabelle A Stack' \\ Jane I Zimmerman ${ }^{4}$ \\ Anthony W Russell ${ }^{4,5}$ \\ Lauren E Ball ${ }^{6}$ \\ Ingrid J Hickman ${ }^{1,7}$ \\ 'Department of Nutrition and \\ Dietetics, Princess Alexandra Hospital, \\ ${ }^{2}$ School of Human Movement and \\ Nutrition Sciences, The University \\ of Queensland, ${ }^{3}$ INNIS Partnership, \\ Brisbane, ${ }^{4}$ Department of Diabetes \& \\ Endocrinology, Princess Alexandra \\ Hospital, ${ }^{5}$ School of Medicine, \\ University of Queensland, 'Menzies \\ Health Institute Queensland, \\ Griffith University, ${ }^{7}$ The Mater \\ Research Institute, The University of \\ Queensland, Brisbane, QLD, Australia
}

Correspondence: Ingrid J Hickman Department of Nutrition and Dietetics, Ground Floor, Building 15, Princess Alexandra Hospital, Ipswich Road, Woolloongabba, QLD 4102, Australia

$\mathrm{Tel}+6|73| 765588$

Fax +61731765619

Email i.hickman@uq.edu.au
Background: Insightful accounts of patient experience within a health care system can be valuable for facilitating improvements in service delivery.

Objective: The aim of this study was to explore patients' perceptions and experiences regarding a tertiary hospital Diabetes and Endocrinology outpatient service for the management of type 2 diabetes mellitus (T2DM).

Method: Nine patients participated in discovery interviews with an independent trained facilitator. Patients' stories were synthesized thematically using a constant comparative approach.

Results: Three major themes were identified from the patients' stories: 1) understanding T2DM and diabetes management with subthemes highlighting that specialist care is highly valued by patients who experience a significant burden of diabetes on daily life and who may have low health literacy and low self confidence; 2) relationships with practitioners were viewed critical and perceived lack of empathy impacted the effectiveness of care; and 3) impact of health care systems on service delivery with lack of continuity of care relating to the tertiary hospital model and limitations with appointment bookings negatively impacting on patient experience.

Discussion: The patients' stories suggest that the expectation of establishing a productive, ongoing relationship with practitioners is highly valued. Tertiary clinics for T2DM are well placed to incorporate novel technological approaches for monitoring and follow-up, which may overcome many of the perceived barriers of traditional service delivery.

Conclusion: Investing in strategies that promote patient-practitioner relationships may enhance effectiveness of treatment for T2DM by meeting patient expectations of personalized care. Future changes in service delivery would benefit from incorporating patients as key stakeholders in service evaluation.

Keywords: diabetes mellitus, discovery interview, health care, personal narratives

\section{Introduction}

Type 2 diabetes mellitus (T2DM) is a chronic disease and a leading cause of morbidity and mortality in Australia. ${ }^{1}$ Up to $5 \%$ of the Australian population has a T2DM diagnosis, although the true prevalence is likely double this rate due to considerable under diagnosis. ${ }^{1}$ Poor glycemic control increases the risk of micro- and macro-vascular complications, which are a significant, yet preventable, burden on the health system. ${ }^{2,3}$ Self-management practices such as dietary behaviors, physical activity, blood glucose monitoring, and wound care are well recognized as supporting optimal glycemic control. ${ }^{4}$ It is paramount that patients are supported to undertake self-management practices to enhance their personal health outcomes and minimize 
the risk of complications. ${ }^{5}$ Patients with T2DM typically receive ongoing care from a variety of health professionals either in primary or tertiary health care settings. ${ }^{6}$ Optimizing the delivery of health services in these settings may benefit health outcomes.

Health care service models are traditionally founded on studies with health and economic outcomes. ${ }^{7,8}$ However, there is currently limited awareness of consumers' perspectives about their health care experiences and expectations, and opportunities to collect this information are not typically embedded in health care systems. ${ }^{9}$ This information is a key component of patient-centered care in which patients are incorporated as "partners" to ensure quality, appropriate care is provided. ${ }^{10}$ The concept of partnering with patients has been endorsed by the World Health Organization for the globalized effort to redesign and improve health care processes, including the need to better understand the "patient journey" across the health care continuum. ${ }^{11}$

Previous investigations of patients' health care experiences for T2DM have often used quantitative approaches, such as surveys, ${ }^{12,13}$ which tend to overestimate patients' satisfaction with services. ${ }^{14}$ In addition, qualitative focus groups are usually guided by predetermined questions and may result in truncated storytelling by patients, which limits the understanding of patients' perspectives. ${ }^{15,16}$ Discovery interviews have been used extensively within the UK to gain unbiased consumer insights to inform service improvement activities. ${ }^{17,18}$ The discovery interview technique provides the opportunity for consumers to tell their experiences or "stories" as opposed to the traditional questioning approach. ${ }^{17,19}$ This process values the principles of consumer perspectives and priorities, considering consumers as the experts on how health conditions impact their day to day life, rather than asking for a judgment or assessment of the health care service. ${ }^{17,20}$ Individual interviewing techniques can serve to overcome a fear of sharing and influence of contrasting views which may be encountered within group settings, serving as a valuable first line approach to better understanding consumer experiences.

Therefore, the aim of this study was to undertake discovery interviews that explore patients' perceptions and experiences regarding a tertiary hospital Diabetes and Endocrinology outpatient service.

\section{Methods}

This study undertook discovery interviews to explore patients' perceptions and experiences regarding a tertiary hospital diabetes and endocrine outpatient service. Discovery interviews are a qualitative approach that facilitates participants to share an open "story" prompted by an interview "spine" of laminated cards containing key words and phrases as determined by the researchers. ${ }^{19,20}$ Ethical approval was granted by the Metro South Hospital and Health Service's Human Research Ethics Committee (Brisbane, QLD, Australia).

Purposive sampling ${ }^{21}$ was used to identify patients of interest who had been referred to a tertiary hospital outpatient clinic in Brisbane, Australia, for management of T2DM. Potential participants were selected using the outpatient appointment management system in July 2013. The discovery interview approach is not designed to reach saturation of data but rather to generate rich empirical material describing the patient experience which provides insights that are not typically revealed using survey or structured interview approaches. New and informative insights can be gleaned from a small number of interviews. The number of interviews undertaken in this study was therefore determined by the time and resources available to the research team. A list of patient names was randomly generated; these patients were telephoned by hospital staff to describe the aim of the study and ascertain interest in participation. Verbal consent was obtained for contact details to be provided to independent researchers trained in conducting discovery interviews. Of the 32 people who had agreed to participate, nine were approached by independent researchers and informed written consent was then obtained prior to conducting each discovery interview. The identity of these nine participants was blinded to clinic staff to ensure anonymity.

An interview spine was developed to form a basic prompt for consumers in sharing their story of the health care experience. ${ }^{17}$ The prompt words included in the spine consisted of "Living with diabetes", "Taking responsibility", "Seeking help and support", "Having expectations", "Seeing the dietitian", "Changing my life", "Being heard", "Understanding diabetes", and "Making progress". Prompts were devised via rationally derived discussion within the research team, which was comprised of experienced clinicians and qualitative researchers with experience in the discovery interview technique. The aim was to develop a spine that allowed the stories generated to address the aims of the study without being deemed leading or judgmental. Trained interviewers conducted individual face-to-face interviews with participants. Prompts or probing questions were kept to a minimum, but were used as appropriate to encourage participants to continue telling their story. ${ }^{17}$ The discovery interviews were recorded using a digital Dictaphone and transcribed as patients' stories. 
Patients' stories were synthesized thematically using a constant comparative approach informed by current patient-centered care philosophies within chronic disease management. ${ }^{22}$ Firstly, JC coded sections of the transcripts and organized these into groups with common themes. Secondly, JC and LB further developed the themes by discussing their dimensions and properties for each participant. Post-analysis discussion and verification of themes were conducted among JC, LB, MF, and IH to identify common or dissident viewpoints among interviewed participants. Triangulation was achieved through the involvement of the clinic psychologist (JZ) verifying interpretation. Participant quotes were used to support the key themes and coded in sequential numbers such as P1 = participant 1.

\section{Results}

Nine patients (two male and seven female), average age 56 years, receiving care from the diabetes clinic participated in the discovery interviews. Thematic analysis of the stories identified three major themes with multiple sub-themes, as displayed in Table 1.

\section{Theme I: understanding diabetes and diabetes management Specialist diabetes management is highly valued by patients}

The value of specialist care, above and beyond general practitioner (GP) management, was highly evident in the patients' stories. Patients valued their relationships with their GP; however, they perceived the role of their GP to be focused on routine health care services such as script provision, general check-ups, and monitoring. Patients perceived that significant health conditions, such as T2DM, required the expertise of specialists for ideal management.
I prefer to be under [hospital] rather than my GP, probably because they are the experts in a particular field. I have a wonderful GP, but she doesn't have the expertise to handle all my particular problems. (P1)

I'm glad to be going to the diabetes clinic, and glad of that opportunity to be going there to have them keeping any eye on my diabetes. Because I just feel that I need somebody with that level of understanding of the diabetes to help me get a better understanding of it. (P4)

\section{Diabetes is forever}

Participants commonly felt that once they received the diagnosis of diabetes, it could not be improved or resolved, and was a significant impact upon their quality of life. Participants also reported difficulty coming to terms with the diagnosis and the chronic nature of the condition.

In my culture having diabetes is sort of like a death sentence. It's like cancer, 'oh my God, you're terminally ill', is how they take it there. (P7)

It [having diabetes] is challenging you know. I tell you, it's the worst thing that could happen to anyone. Once you get it, the fun is over. I've accepted that I have diabetes. I've accepted it and that's it, and there's no way out. (P5)

\section{Diabetes is a significant burden on daily life}

Participants reported that the daily imposition of decisions or behaviors necessary for diabetes management was a challenge and posed a significant workload burden on their lives.

I do have difficulties living with my diabetes. I don't always have enough money, and I find it hard trying to choose what can fit with my diabetes side of things... I got my diabetes, I got sleep apnea. I've got the renal side to worry about. I've

Table I Major response themes identified from interviews

\begin{tabular}{|c|c|}
\hline Theme & Subthemes \\
\hline Understanding diabetes and diabetes management & $\begin{array}{l}\text { - Specialist diabetes management is highly valued by patients } \\
\text { - Diabetes is forever } \\
\text { - Diabetes is a significant burden on patients' daily life } \\
\text { - Limitations in health literacy, self-efficacy, and self-management skills remain } \\
\text { unspoken during the health service experience }\end{array}$ \\
\hline Relationships with health care professionals & $\begin{array}{l}\text { - Patients need health care professionals to display empathy toward them } \\
\text { - Patients expect health care professionals to build relationships with them } \\
\text { - Patients need education provided in a format that meets their needs }\end{array}$ \\
\hline Impact of health care systems on service delivery & $\begin{array}{l}\text { - There is a lack of continuity of care } \\
\text { - There are limitations with the appointment scheduling system } \\
\text { - There are excessive waiting times in clinic prior to an appointment }\end{array}$ \\
\hline
\end{tabular}


got my feet to worry about, and then I've got my once a year with the eye specialist and then there's the optometrist I see as well. What else is there? And then there's my regular fortnightly appointments with my GP and then I've got to get my back sorted out. It's not easy. Not easy. (P2)

If my diabetes gets worse then I will be a burden to the family. I don't want to be a burden to my family and my wife. What would happen to us? (P3)

\section{Limitations in health literacy, confidence,} and self-management skills remain unspoken during the health service experience

Participants indicated personal barriers to self-management including knowledge, confidence, competing priorities, and low levels of self-efficacy, which were challenging to discuss during interactions with health staff.

I suppose I'm just getting to understand the diabetes ... So I'm just learning, I do need more input into the understanding of it. (P4)

I don't really understand the pancreas and the insulin and all that. (P5)

I started giving myself that needle, the educator said to ring them up. But when you ring them up you find they're only there for certain times of the day. I was so confused, but I kept doing it and then last month I stopped it because my stomach was so sore... I've been off it for one month now and I haven't told my doctor or I haven't told the diabetic nurses or anyone that I've stopped taking it. But I thought I'd give myself a month off it and see how I go. I'm always thinking, am I doing the right thing? I'm not sure, but I'm just doing it because that's what the doctors say. (P5)

\section{Theme 2: relationships with health care professionals Patients need health care professionals to display empathy toward them}

In their stories, participants used language that suggested not all health care professionals demonstrated an understanding of the challenge and burden of a diabetes diagnosis.

Sometimes I wish they could be in my shoes... I don't know if they really fully understand what a struggle it is. (P2)

At the clinic it is usually don't, don't, don't [laughs]. They think you are an idiot. (P8)
I mean, people don't know you, you know. ... When I go there, I have felt like I am going to see the principal at the school. (P8)

[The Dietitian] seems to know what they are talking about and there's a sense that they are sensitive and caring enough to know and worry what's happening to me. You can tell because of the way they speak to you. (P2)

\section{Patients expect health care professionals to build relationships with them}

Participants described limited relationships with health care professionals, which appeared to limit effective and productive health care partnerships. A variety of factors contributed to limited relationships, including frequent rotation of clinic staff limiting continuity of care, a feeling of limited time to develop a relationship, and ineffective communication with patients.

My GP is different, they're engaged. I guess they get to know you and so they know you and so they know if you are telling them the truth and you are not just making up an excuse. You build up a relationship with them. Whereas, when you go to the hospital, you see someone different every time and you can never build up any sort of relationship with them. They are there for a time and then they go onto a different section. When you try and explain something to them, they don't know you, they wouldn't have a clue, anything about you, or your life or anything. (P8)

Sometimes it feels like, the doctor just wants you to get in and get out again type of feeling. Sometimes I'm in and out straight away and other times I'm waiting around for ages, and then I'm thinking, I don't know what they're doing in there. Why are they taking so long in seeing me? I just think you get so used to being treated that way, just go in and they say what they have to say and go out again, really. I feel like that was a bit of a waste of time. (P2)

They are just run off their feet, busy, and they haven't got time, you are a number, there is your blood test. (P8)

There just wasn't that friendliness, that personal touch... that personal touch that's needed. (P4)

I found... when I was talking to the Dietitian, she was quite sensitive, quite supportive... that keeps me going. I think it's [because] their heart's there. (P2)

\section{Patients need education provided in a format that meets their needs}

Participants reported having limited understanding about the education provided by health care professionals, predominantly due to inappropriate communication approaches. 
You can't really understand what they're saying. (P1)

They tried to explain this and it went over my head. (P2)

Once I saw the dietitian and I didn't feel I was getting enough information from them. They just go through the pages, and then they give me out all these pamphlets. But, I find they go too quick... I come home with all these pamphlets and folders and then, of course, I just put them there on the side thinking, yeah, I'll read them later on but never come around to it. (P5)

When I come and I look at them [education resources], I get really confused. (P5)

I found I got more help off the net, than talking to the doctors and stuff. (P8)

... the Dietitian used to sit with me and we'd just do a one to 10 on how I was feeling... how full you feel, things like that... it was really good. (P2)

\section{Theme 3: impact of health care systems on service delivery There is a lack of continuity of care}

Participants experienced considerable frustration with the diabetes service due to seeing multiple health care professionals over time, limiting continuity of care. Patients felt that recounting their medical history at each visit was not a constructive process and limited progress in their diabetes management. This was also highlighted as a significant contributor to unproductive health care partnerships due to the health care professionals' superficial understanding of the individual's personal circumstances, history, and goals.

Who are we seeing today?... It does get me down especially when you go in and you see another doctor, another new doctor who sits there and says 'Now, tell me what's wrong.' And I think, oh God, do I have to go through it all again... It's a waste of time me going to see people like that because they've got no idea really what's going on with you. (P1)

Frustrating. In the nine years that I've been going to the [hospital], I've never seen the same doctor. I had this one patch where I saw the doctor that I'm supposed to be seeing. I think I would have probably seen him weekly just because they wanted to keep an eye on my diabetes. But every time I've gone in since then, it's been another doctor or somebody else. I've never had that continuity, I've always had people wanting me to backtrack to, recap on last week's episode and it's never been, okay, let's go from here, yeah, let's move forward, it's always been let's move back a bit. (P9)

But the thing is I come home and then I'll come across something and I want to ring them up and as soon as I do ring them up they're not available because they're not working that day. And so that turns me off - you know, how you ring someone and they don't answer. (P5)

\section{There are limitations with the appointment scheduling system}

Patients' stories highlighted limitations with the appointment scheduling system, predominantly a lack of flexibility in appointment booking, clinic times, and processes. Participants regularly reflected on instances of merely attending appointments to stay within the system or due to fear of losing contact with specialist services. Other participants described a desire for greater contact with the clinic for additional support and monitoring. Participants reported difficulties in managing other commitments around appointments because of limited notification of upcoming appointments, and this contributed to regular cancellations or re-scheduling of appointments.

'Oh, come and see me in a month's time,' and you try to make the appointment and you can't. That time I didn't see them until five or six months later down the track. So here I am doing this thing that I don't even know what I'm doing to my body and I just need a confirmation, everything is okay. (P5)

Sometimes we walk out and say that was a waste of time. Because if nothing has happened over the three months, it's been uneventful you're really going to an appointment because you've got an appointment and you have to go to your appointments because if you don't you don't get another appointment. (P1)

It was either turn up or this is it. I couldn't turn up. I was leaving the country and it was just - I actually can't make it. (P9)

I don't get my roster till the week before, I often have to reschedule my appointment. (P9)

By the time they get a [appointment] letter, my roster's out for work. (P7)

\section{There are excessive waiting times in clinic prior to an appointment}

Participants reported significant frustration with extended waiting times immediately prior to a scheduled appointment, which impacted upon future attendance and appointment re-scheduling. Participants who were unable to allocate an 
extended period of time to attend an appointment were forced to re-schedule their appointment.

Why are they taking so long in seeing me? (P2)

You go in there for a 10 o'clock appointment, you're still there at 2 o'clock. That's probably why most of my appointments get cancelled because you literally have to clear your entire schedule for that day. (P9)

You'd sit there and you'd wait and you'd wait and you'd wait. (P5)

\section{Discussion}

This study contributes new information on patients' experiences of a tertiary hospital T2DM service, which can be used to inform patient-centered health care service delivery. Participants provided rich and meaningful insights on factors that affect their health care experiences. Three major themes were generated from patients' stories, which identified clear opportunities for improvement in service delivery, including continuity of care, communication, and appointment bookings. This information is important due to the recognized relationship among health care experiences, self-management practices, and health care outcomes. ${ }^{13}$

The patients' stories clearly highlight the value placed on investing in developing partnerships between health care professionals and patients. A perceived lack of personalized service and low health literacy has the potential to limit the effectiveness of prescribed treatment options for chronic disease. Low health literacy may be associated with difficulty interpreting health information, rather than a diminished desire for information, ${ }^{23}$ and the results of this study support this notion. When health literacy is measured and accommodated through tailored education material, diabetes knowledge can rapidly improve. ${ }^{24}$ The inclusion of infographics in education material, carefully designed with the input of patients, can provide valuable context for health information, support comprehension, and may facilitate the steps toward self-management actions. ${ }^{23}$ Health literacy is complex and rarely measured in clinical trials. ${ }^{25}$ The development of validated tools to measure different components of health literacy as intermediary outcomes of clinical services seems warranted. Service delivery models or communication styles that do not meet patients' expectations of shared decision making are likely to compound barriers to effective care. Involving patients in education and decision making has been shown to enhance health literacy ${ }^{25}$ and confidence in self-management. ${ }^{26}$ This is noteworthy because enhanced confidence in self-management is likely to result in improved outcomes for patients. ${ }^{4,27}$ Despite a desire to be involved in decision making associated with the management of T2DM, participants acknowledged and highly valued the specialist expertise of the tertiary health care team. It was evident that the partnerships among specialist, GP, and patient could be more clearly defined for each individual. Education that is structured with provisions for patient-directed priorities and expectations and agreed upon roles for GPs and other practitioners may positively influence the perception of individualized care. ${ }^{28}$ Patient empowerment has gained prominence in health care as an indicator for patient-centered care. This study identified a number of factors which may act as indicators for patient empowerment, ${ }^{29}$ including health literacy, feeling respected, and involved in decision making. Measuring indicators of patient empowerment ${ }^{29}$ could be an innovative way of evaluating service delivery in the future.

The patients' stories suggest that establishing a productive, ongoing relationship with health care professionals is highly valued but currently unmet. A number of factors impeded the development of relationships including regular staff rotation and perceived lack of empathy. Rotation of training medical staff through tertiary centers is presently an unavoidable obligation of teaching hospitals. Innovative strategies to improve handover of patient care to new staff need to be considered. Bedside nursing handover is an example whereby improvements in facilitated handover between staff (possibly using standardized tools) has empowered patients to participate in the care process. ${ }^{30,31}$ The burden of extended time between appointments makes the outpatient environment quite different to inpatient care; however, investing in developing modified standardized handover tools to suit outpatient settings, real time case conference discussions during clinic, multidisciplinary team meetings, utilizing non-rotating nursing staff to act as case managers, and embracing the developing robotic technologies ${ }^{32,33}$ could all contribute to reducing the dissatisfaction felt when patients need to regularly repeat their history. The health care system is likely to be transformed by artificial intelligence devices which will enhance the flow of information between patient and health care professional and assist decision making and personalized medicine. ${ }^{34,35}$ It appears from this study that tertiary based clinics for T2DM are a salient target to test these innovations as a strategy to enhance patient-physician relationships.

The perceived degree of empathy felt during a consultation is critical for building relationships with patients. ${ }^{36,37}$ Empathy is complex and can be described as a caregiver understanding the private world of the client to gain insight into their situation without judgment. ${ }^{38}$ The way it is displayed can 
be influenced by an individual's personality and his or her own experienced emotions. There is a link between an individual physician's well-being and the quality of care delivered within the workplace. ${ }^{39}$ Compassion fatigue is a gradual lessening of compassion over time in caregivers who are regularly exposed to patients' problems. This has most commonly been measured in professionals dealing with daily trauma victims, but the phenomenon may also occur for health professionals involved in long-term health care of conditions which have no cure. ${ }^{40}$ Strategies to acknowledge and support the well-being of staff involved in chronic care including stress reduction and resilience ${ }^{41}$ and social support/team building exercises could have collateral benefits for improving perceived empathy with patients. Furthermore, incorporating patients' stories into evaluations of service delivery models or regular clinic meetings may remind staff to be more aware of patients' experiences of the service. ${ }^{42}$

Numerous system issues impacted upon the health services provided to patients, including lack of flexibility in booking appointments, long waiting times at the clinic, and lack of continuity of care. While the need for improvements in the logistical management of tertiary health services is not a new issue, it is still a critical factor in patients' perception of quality care and may impact on patients' health outcomes. ${ }^{43}$ Logistical modifications appear warranted to ensure the delivery of appointments meet patients' needs and may require the use of flexible consultation times (wave booking system), after-hours appointment times, or telehealth technology. Telehealth programs for patients with T2DM have been shown to elicit improvements in self-management practices and health outcomes. ${ }^{44,45}$ Again, partnering with patients to determine the most beneficial delivery of services and embracing emerging artificial intelligence monitoring systems for patients to avoid physical attendance at clinic altogether ${ }^{46}$ may facilitate appropriate prioritization of flexible service delivery options.

Storytelling is becoming increasingly recognized in health care as a powerful tool that can be used to better understand patient experiences and thereby facilitate health care service improvement. ${ }^{19}$ The local dissemination of the patients' stories from this study has initiated conversations across a broad range of stakeholders including front line clinic staff, middle and executive management, research institute staff, research funding bodies, and local and national health professional conferences. The stories have been used to generate discussion about service development strategies, improvement in research protocol development, and have highlighted the value of community engagement in the development and design of translational research activity.

This study has some noteworthy limitations. First, it is unclear whether lessons learned in one tertiary setting can be successfully transferred to other settings. ${ }^{19}$ However, the patient experiences captured in this study align closely with other evaluations of diabetes management, such as in the primary care setting, and suggest that shared learning across settings may be possible. ${ }^{47}$ Second, the limited number of patients' stories and sex bias toward greater female participants means that it is possible that other patients who did not participate in the study had experiences that have not been captured. In addition, staff perceptions were not captured in this study and there was no cross-check linking patient experience with clinical outcome. Rather than identifying definitive systems issues, the utilization of discovery interviews is most highly regarded to hear detailed stories from a small number of people, which can then provide ideas for service improvement. ${ }^{17}$ In addition to discovery interviews, alternative strategies that might typically be restricted to research studies such as patient focus groups could inform practical strategies for developing format, content, and delivery options to meet their needs and could be embedded into annual clinical review processes. Consideration of adopting these strategies across other chronic diseases such as cardiovascular disease, respiratory disease, and hypertension is also relevant.

In conclusion, this study provides valuable information regarding patients' experience of a tertiary hospital T2DM service. Investing in strategies that enhance the perception of empathetic relationships with the health practitioner and health literacy may enhance effectiveness by meeting patient expectations of personalized care. These insights highlight that active consumer participation is not embedded in the current health care setting. Future changes in the service delivery would benefit from incorporating patients as key stakeholders in service evaluation and improvement. The utilization of patients' stories as a regular strategy for service evaluation is encouraged.

\section{Acknowledgments}

Funding was received from Diabetes Australia Queensland, Diabetes Translational Research Grant 2013. The authors would like to thank all staff and patient participants from the Department of Diabetes and Endocrinology at the Princess Alexandra Hospital, Brisbane.

\section{Disclosure}

The authors report no conflicts of interest in this work. 


\section{References}

1. Australian Institute of Health and Welfare. Cardiovascular disease, diabetes and chronic kidney disease-Australian facts: Prevalence and incidence. Canberra: AIHW; 2014.

2. Andrews RC, Cooper AR, Montgomery AA, et al. Diet or diet plus physical activity versus usual care in patients with newly diagnosed type 2 diabetes: the Early ACTID randomised controlled trial. Lancet. 2011;378(9786):129-139.

3. Cooper AJM, Schliemann D, Long GH, et al. Do improvements in dietary behaviour contribute to cardiovascular risk factor reduction over and above cardio-protective medication in newly diagnosed diabetes patients? Eur J Clin Nutr. 2014;68(10):1113-1118.

4. Bastiaens H, Sunaert P, Wens J, et al. Supporting diabetes selfmanagement in primary care: pilot-study of a group-based programme focusing on diet and exercise. Prim Care Diabetes. 2009;3(2):103-109.

5. Higgins R, Murphy B, Worcester M, Daffey A. Supporting chronic disease self-management: translating policies and principles into clinical practice. Aust J Prim Health. 2012;18(1):80-87.

6. Diabetes Australia. Diabetes in Australia Canberra 2012 [cited 2012 November]. Available from: www.diabetesaustralia.com.au/ Understanding-Diabetes/Diabetes-in-Australia

7. King P, Peacock I, Donnelly R. The UK prospective diabetes study (UKPDS): clinical and therapeutic implications for type 2 diabetes. Br J Clin Pharmacol. 1999;48(5):643-648.

8. Ajala O, English P, Pinkney J. Systematic review and meta-analysis of different dietary approaches to the management of type 2 diabetes. Am J Clin Nutr. 2013;97(3):505-516.

9. Greaves F, Millett C, Nuki P. England's Experience incorporating "anecdotal" reports from consumers into their national reporting system: lessons for the United States of what to do or not to do? Med Care Res Rev. 2014;71(5 Suppl):65S-80S.

10. McWilliam CL. Patients, persons or partners? Involving those with chronic disease in their care. Chronic Illn. 2009;5(4):277-292.

11. World Health Organization. London Declaration: Patients for Patient Safety. Geneva, Switzerland: WHO; 2006.

12. Ball L, Hughes R, Desbrow B, Leveritt M. Patients' perceptions of nutrition care provided by general practitioners: focus on Type 2 diabetes. Fam Pract. 2012;29(6):719-725.

13. Sequist TD, Von Glahn T, Li A, Rogers WH, Safran DG. Measuring chronic care delivery: patient experiences and clinical performance. Int J Qual Health Care. 2012;24(3):206-213.

14. Alazri MH, Neal RD. The association between satisfaction with services provided in primary care and outcomes in Type 2 diabetes mellitus. Diabet Med. 2003;20(6):486-490.

15. Wilcock PM, Brown GCS, Bateson J, Carver J, Machin S. Using patient stories to inspire quality improvement within the NHS Modernization Agency collaborative programmes. J Clin Nurs. 2003;12:422-430.

16. Sandelowski M. Telling stories: narrative approaches in qualitative research. Image J Nurs Sch. 1991;23(3):161-166.

17. NHS Modernisation Agency. Learning from Patients and Carer Experience: A Guide for Using Discovery Interviews to Improve Care. Leicester: NHS Modernisation Agency; 2004.

18. Bridges J, Nicholson C. Service improvement using patient narratives: engaging with the issues. Int J Older People Nurs. 2008;3(3):217-222.

19. Bridges J, Gray W, Box G, Machin S. Discovery interviews: a mechanism for user involvement. Int J Older People Nurs. 2008;3(3):206-210.

20. NHS Heart Improvement Programme. A skills-based operational framework for Practitioners with a Special Interest in Cardiology. Leicester: NHS Heart Improvement Programme; 2007.

21. Silverman D. Interpreting Qualitative Data. 3rd ed. London: Sage Publications Ltd; 2010.

22. Strauss AL, Corbin JM. Basics of Qualitative Research: Techniques and Procedures for Developing Grounded Theory. Thousand Oaks: Sage Publications; 1998.

23. Arcia A, Suero-Tejeda N, Bales ME, et al. Sometimes more is more: iterative participatory design of infographics for engagement of community members with varying levels of health literacy. J Am Med Inform Assoc. Epub 2015 Jul 13.
24. Koonce TY, Giuse NB, Kusnoor SV, Hurley S, Ye F. A personalized approach to deliver health care information to diabetic patients in community care clinics. J Med Libr Assoc. 2015;103(3):123-130.

25. Taggart J, Williams A, Dennis S, et al. A systematic review of interventions in primary care to improve health literacy for chronic disease behavioral risk factors. BMC Fam Pract. 2012;13:49.

26. Mirzaei M, Aspin C, Essue B, et al. A patient-centred approach to health service delivery: improving health outcomes for people with chronic illness. BMC Health Serv Res. 2013;13(1):251.

27. Rose V, Harris M, Ho MT, Jayasinghe UW. A better model of diabetes self-management? Interactions between GP communication and patient self-efficacy in self-monitoring of blood glucose. Patient Educ Couns. 2009;77(2):260-265.

28. Glasgow RE, Peeples M, Skovlund SE. Where is the patient in diabetes performance measures? The case for including patientcentered and self-management measures. Diabetes Care. 2008;31(5): $1046-1050$

29. Bravo P, Edwards A, Barr PJ, et al. Conceptualising patient empowerment: a mixed methods study. BMC Health Serv Res. 2015;15:252.

30. Anderson J, Malone L, Shanahan K, Manning J. Nursing bedside clinical handover - an integrated review of issues and tools. $J$ Clin Nurs. 2015;24(5-6):662-671.

31. Lu S, Kerr D, McKinlay L. Bedside nursing handover: patients' opinions. Int J Nurs Pract. 2014;20(5):451-459.

32. Hernandez D. Robo-Doctors signal the rise of the medical machines 2012 [cited 2015 March]. Available from: http://www.wired. com/2012/10/intouch-robo-doctors/

33. Cohn J. The robot will see you now. Atl Mon. 2013;311(2):59-67.

34. Fineberg HV. Shattuck Lecture. A successful and sustainable health system - how to get there from here. $N$ Engl J Med. 2012;366(11): 1020-1027.

35. Topol E. The Patient Will See You Now: The Future of Medicine Is in Your Hands. New York: Basic Books; 2015.

36. Reynolds WJ, Scott B. Empathy: a crucial component of the helping relationship. J Psychiatr Ment Health Nurs. 1999;6(5):363-370.

37. Kowitt SD, Urlaub D, Guzman-Corrales L, et al. Emotional support for diabetes management: an international cross-cultural study. Diabetes Educ. 2015;41(3):291-300.

38. Mercer SW, Reynolds WJ. Empathy and quality of care. Br J Gen Pract. 2002;52 Suppl:S9-S12.

39. Wallace JE, Lemaire JB, Ghali WA. Physician wellness: a missing quality indicator. Lancet. 2009;374(9702):1714-1721.

40. Shrestha D, Joyce CM. Aspects of work-life balance of Australian general practitioners: determinants and possible consequences. Aust J Prim Health. 2011;17(1):40-47.

41. Potter P, Pion S, Gentry JE. Compassion fatigue resiliency training: the experience of facilitators. J Contin Educ Nurs. 2015;46(2): $83-88$.

42. Reynolds WJ, Scott B, Jessiman WC. Empathy has not been measured in clients' terms or effectively taught: a review of the literature. $J$ Adv Nurs. 1999;30(5):1177-1185.

43. Diabetes Australia, Royal Australian College of General Practitioners. Diabetes Management in General Practice: Guidelines for Type 2 Diabetes. 14th ed. 2008.

44. Goode AD, Winkler EAH, Lawler SP, Reeves MM, Owen N, Eakin EG. A telephone-delivered physical activity and dietary intervention for type 2 diabetes and hypertension: does intervention dose influence outcomes? Am J Health Promot. 2011;25(4):257-263.

45. Shea S, Weinstock RS, Starren J, Teresi J, for the IC. A randomized trial comparing telemedicine case management with usual care in older, ethnically diverse, medically underserved patients with diabetes mellitus. J Am Med Inform Assoc. 2006;13(1):40-51.

46. Hayes DF, Markus HS, Leslie RD, Topol EJ. Personalized medicine: risk prediction, targeted therapies and mobile health technology. $B M C$ Med. 2014;12:37.

47. Kaissi AA, Parchman M. Organizational factors associated with selfmanagement behaviors in diabetes primary care clinics. Diabetes Educ. 2009;35(5):843-850. 
Patient Preference and Adherence

Dovepress

\section{Publish your work in this journal}

Patient Preference and Adherence is an international, peer-reviewed, open access journal that focuses on the growing importance of patient preference and adherence throughout the therapeutic continuum. Patient satisfaction, acceptability, quality of life, compliance, persistence and their role in developing new therapeutic modalities and compounds to optimize

Submit your manuscript here: http://www.dovepress.com/patient-preference-and-adherence-journ clinical outcomes for existing disease states are major areas of interest for the journal. This journal has been accepted for indexing on PubMed Central. The manuscript management system is completely online and includes a very quick and fair peer-review system, which is all easy to use. Visit http://www. dovepress.com/testimonials.php to read real quotes from published authors. 